\title{
Bcl2L12 inhibits post-mitochondrial apoptosis signaling in glioblastoma
}

\author{
Alexander H. Stegh, ${ }^{1}$ Hyunggee Kim, ${ }^{1,9}$ Robert M. Bachoo, ${ }^{1,2}$ Kristin L. Forloney, ${ }^{1}$ Jean Zhang, ${ }^{1,3}$ \\ Harald Schulze, ${ }^{1}$ Kevin Park, ${ }^{4}$ Gregory J. Hannon, ${ }^{5}$ Junying Yuan, ${ }^{6}$ David N. Louis, ${ }^{4}$ \\ Ronald A. DePinho, ${ }^{1,3,7,11}$ and Lynda Chin ${ }^{1,3,8,10}$ \\ ${ }^{1}$ Department of Medical Oncology, Dana-Farber Cancer Institute, Boston, Massachusetts 02115, USA; ${ }^{2}$ Center for \\ Neuro-Oncology and Department of Neurology, Brigham and Women's Hospital, Boston, Massachusetts 02115, USA; \\ ${ }^{3}$ Center for Applied Cancer Science and the Belfer Foundation Institute for Innovative Cancer Science, Dana-Farber Cancer \\ Institute, Boston, Massachusetts 02115, USA; ${ }^{4}$ Department of Pathology, Cancer Center and Neurosurgical Service, \\ Massachusetts General Hospital and Harvard Medical School, Boston, Massachusetts 02115, USA; ${ }^{5}$ Watson School of \\ Biological Sciences, Cold Spring Harbor Laboratory, Cold Spring Harbor, New York 11724, USA; ${ }^{6}$ Department of Cell \\ Biology, Harvard Medical School, Boston, Massachusetts 02115, USA; ${ }^{7}$ Department of Medicine and Department of \\ Genetics, Harvard Medical School, Boston, Massachusetts 02115, USA; ${ }^{8}$ Department of Dermatology, Harvard Medical \\ School, Boston, Massachusetts 02115, USA
}

Glioblastoma (GBM) is an astrocytic brain tumor characterized by an aggressive clinical course and intense resistance to all therapeutic modalities. Here, we report the identification and functional characterization of Bc12L12 (Bcl2-like-12) that is robustly expressed in nearly all human primary GBMs examined. Enforced Bc12L12 expression confers marked apoptosis resistance in primary cortical astrocytes, and, conversely, its RNA interference (RNAi)-mediated knockdown sensitizes human glioma cell lines toward apoptosis in vitro and impairs tumor growth with increased intratumoral apoptosis in vivo. Mechanistically, Bcl2L12 expression does not affect cytochrome c release or apoptosome-driven caspase-9 activation, but instead inhibits post-mitochondrial apoptosis signaling at the level of effector caspase activation. One of Bcl2L12's mechanisms of action stems from its ability to interact with and neutralize caspase-7. Notably, while enforced Bc12L12 expression inhibits apoptosis, it also engenders a pronecrotic state, which mirrors the cellular phenotype elicited by genetic or pharmacologic inhibition of post-mitochondrial apoptosis molecules. Thus, Bc12L12 contributes to the classical tumor biological features of GBM such as intense apoptosis resistance and florid necrosis, and may provide a target for enhanced therapeutic responsiveness of this lethal cancer.

[Keywords: Apoptosis; caspase-7; malignant glioma; necrosis]

Supplemental material is available at http://www.genesdev.org.

Received August 9, 2006; revised version accepted November 14, 2006.

Malignant gliomas represent the most common and lethal brain tumors that involve the cerebral hemispheres of adults. The most aggressive manifestation of malignant gliomas is glioblastoma (GBM, Glioblastoma Multiforme), which either arises as de novo high-grade disease (primary GBM) or progresses from low-grade disease to an indistinguishable high-grade disease phenotype (secondary GBM) (Kleihues et al. 2002). The hallmarks of GBM are diffuse invasion, microvascular proliferation (angiogenesis) and extensive necrosis, extreme resistance

\footnotetext{
${ }^{9}$ Present address: Cell growth Regulation Laboratory, Division of Bioscience and Technology, College of Life and Environmental Sciences, Korea University, Seoul 136-701, Korea.

Corresponding authors.

${ }^{10}$ E-MAIL lynda_chin@dfci.harvard.edu; FAX (617) 582-8169.

${ }^{11}$ E-MAIL ron_depinho@dfci.harvard.edu; FAX (617) 632-6069.

Article is online at http://www.genesdev.org/cgi/doi/10.1101/gad.1480007.
}

to all cancer therapies due to robust apoptosis resistance, and rapid clinical progression to death often within 12 mo of diagnosis (for review, see Maher et al. 2001; Zhu and Parada 2002).

Several stereotypical mutations have been identified in high-grade malignant gliomas including Epidermal Growth Factor Receptor (EGFR) activation and Ink4a/ Arf and PTEN loss-of-function mutations (for review, see Maher et al. 2001; Zhu and Parada 2002). In the context of this study, it is worth noting that the intense apoptosis resistance of GBM has been ascribed to many different apoptosis signaling molecules including decoy receptor 3 (DcR3) (Roth et al. 2001a), APRIL (a proliferationinducing ligand) (Hahne et al. 1998; Roth et al. 2001b), PEA-15 (phosphoprotein enriched in astrocytes-15) (HaO et al. 2001), and more generally, overall up-regulation of the Bcl-2 "rheostat" (Strik et al. 1999). 
While resistant to apoptotic stimuli, GBMs typically exhibit extensive necrosis, presenting as foci of micronecrosis surrounded by a broad hypercellular zone contiguous with normal tissue or by parenchymal infiltrates (for review, see Raza et al. 2002; Brat and Van Meir 2004). The mechanistic basis for this necrotic phenotype, particularly in the face of intense apoptosis resistance, is not well understood. A common view suggests that necrosis is a consequence of limited blood supply and anoxia due to a microthrombotic process. While anoxia can be an important driver of necrosis, emerging biochemical and genetic data have provided evidence that necrogenesis intersects with apoptosis signaling pathways on the molecular level (see Discussion). Along these lines, germline deletion of post-mitochondrial apoptosis signaling components, such as Apaf-1, energy depletion, or blockage of effector caspase maturation in the context of apoptosis induction results in decreased apoptosis, yet engenders a dramatic increase in necrosis (for review, see Nicotera and Melino 2004).

Here, in the course of investigating a region of gain on the long arm of chromosome 19 in GBM, we identified and characterized a $\mathrm{BH}-2$ domain-containing and proline domain-rich protein, designated Bcl2L12 (for Bcl2-like12), that showed significant expression in primary GBM. Bcl2L12 confers marked apoptosis resistance and provokes a pronecrotic state in vitro through neutralization of effector caspase-7 activity, and its depletion impairs tumor explant growth associated with increased intratumoral apoptosis in vivo.

\section{Results}

Bcl2L12 possesses unique structural domains and is universally expressed in primary GBM

Within a region of gain on chromosome 19q13, preliminary cell-based assays and expression analyses identified a known gene, Bcl2L12 (Scorilas et al. 2001), with consistent and frequent mRNA up-regulation in GBM relative to normal brain as assessed by quantitative RT-PCR (data not shown). Tissue microarray analysis further revealed robust Bcl2L12 protein expression in 53 of 55 human primary GBM specimens relative to surrounding normal brain tissue (Supplementary Fig. S1; for specificity of the anti-Bcl2L12-2 antiserum, see Supplementary Fig. S4A). Specifically, Bcl2L12 expression was found diffusely throughout the sampled tumors with predominant localization in the tumor cell cytoplasm, but was absent or undetectable in cells of glial origin in low-grade astrocytoma. In normal adult brain adjacent to neoplastic tissue, modest anti-Bcl2L12 immunoreactivity was detected in neurons, without demonstrable positivity in normal glia in the gray or white matter. In addition to diffuse staining throughout the tumor cells, Bcl2L12 was also expressed in endothelial cells within abnormal tumor vasculature (Supplementary Fig. S1).

Bc12L12 bears several cancer-relevant structural motifs that prompted further functional and biochemical investigation. Bcl2L12 possess a C-terminal 14-amino- acid BH2 domain (Supplementary Fig. S2A) that shares significant homology with $\mathrm{BH} 2$ sequences found in other pro- and anti-apoptotic Bcl-2 family proteins (Supplementary Fig. S2B). However, unlike other members of this family, Bcl2L12 does not appear to possess typical $\mathrm{BH} 1, \mathrm{BH} 3$, or $\mathrm{BH} 4$ and transmembrane domains; and accordingly, phylogenetic analyses show lack of clustering with known $\mathrm{BH} 2$ domain-containing Bcl-2 like proteins (Supplementary Fig. S2C). These structural distinctions raised the possibility of nonclassical functional properties of Bcl2L12 (see below).

\section{Bcl2L12 inhibits apoptosis}

The notorious resistance of GBM toward radio- and chemotherapy-induced apoptosis and the focal homology of Bcl2L12 to known apoptosis modulators prompted an extensive series of gain-of-function and loss-of-function studies to assess the impact of Bcl2L12 on apoptosis signaling. In primary cortical astrocytic cultures null for the glioma-relevant tumor suppressor Ink4a/Arf (Zhu and Parada 2002), enforced Bcl2L12 expression increased resistance to staurosporine (STS) over a broad range of STS doses as measured by DNA fragmentation (Fig. 1A) ( $p=0.0032$ for $50 \mathrm{nM}$ STS; $p=0.0061$ for $100 \mathrm{nM}$ STS; $p=0.026$ for $1000 \mathrm{nM} \mathrm{STS}$ ) and AnnexinV staining (data not shown). The level of resistance was comparable to that conferred by activated EGFR (EGFR $\left.{ }^{\star}\right)$ (Fig. 1A, left panel) ( $p=0.05$ for pBabe vs. Bcl2L12), a known GBM oncogene with potent prosurvival and pro-proliferative activities (Nagane et al. 1998). Furthermore, time-course analysis of STS-mediated apoptosis revealed that the significant anti-apoptotic effects of Bcl2L12 were apparent in later phases of apoptosis progression (8-24 h) (Fig. 1B) ( $p=0.036$ for 24-h STS). Bcl2L12 also conferred profound resistance toward apoptosis induced by other death stimuli including camptothecin (CPT), tumor necrosis factor $\alpha(\mathrm{TNF} \alpha)$, and ionizing radiation $(\gamma$-IR $)$, as assessed by quantification of DNA fragmentation and/or a subcloning efficiency assay (Fig. 1C; data not shown) ( $p=0.011$ for $32 \mu \mathrm{M}$ CPT).

We next conducted small interfering RNA (siRNA)mediated knockdown studies in Bcl2L12-expressing GBM cell lines to examine potential modulation of apoptosis resistance. Two independent Bcl2L12-specific siRNAs were verified to be effective in knockdown of Bcl2L12 protein levels (Fig. 1D, top panel). In the glioma cell line U87MG, Bcl2L12 depletion resulted in a significant and consistent sensitization toward STS-induced apoptosis relative to nontargeting siRNA control (siNT) (Fig. 1D) ( $p<0.0001$ for siNT vs. siL12-1 and siL12-2 at 2 $\mu M$ STS). Similar results were obtained with three additional glioma cell lines-LNZ308, LN443, and LN382or with stable knockdown short hairpin RNA (shRNA) vectors (data not shown). Thus, Bcl2L12 is a potent antiapoptotic protein that protects primary cortical astrocytes from drug-, DNA damage-, and death receptor-mediated apoptosis and, reciprocally, its depletion sensitizes different human glioma cell lines toward apoptosis.

The anti-oncogenic impact of Bcl2L12 knockdown 
Figure 1. Bcl2L12 inhibits apoptosis. (A) Ink4a/Arf $f^{-/}$ astrocytes stably expressing pBabe, $\mathrm{Bcl} 2 \mathrm{~L} 12^{\mathrm{V} 5}$, or $\mathrm{EGFR}^{\star}$ were treated with the pan-specific kinase inhibitor STS for $24 \mathrm{~h}$ at a concentration of $10 \mathrm{nM}$ (left) and with increasing doses of STS for $20 \mathrm{~h}$ (right). Apoptosis was measured by FACS-based quantification of DNA fragmentation. (B) pBabe- and Bcl2L12-expressing astrocytes were treated with $1 \mu \mathrm{M}$ STS for the indicated periods of time, and DNA fragmentation was assessed. The $p$ value was calculated for the 24 -h time point. $(C)$ DNA fragmentation of Ink4a/Arf-deficient astrocytes expressing $\mathrm{pBabe}$ or $\mathrm{Bcl} 2 \mathrm{~L} 12^{\mathrm{V} 5}$ treated with $\mathrm{CPT}$ at indicated dosages was measured by FACS-based quantification of sub-G1 DNA content. The $p$ value was calculated for the $32 \mu \mathrm{M}$ doses. $(D, t o p)$ Efficient knockdown of Bcl2L12 in U87MG glioma cells by two independent siRNAs (siL12-1 and siL12-2) relative to nontargeting control (siNT) was documented by Western blot analysis at $48 \mathrm{~h}$ post-transfection using the anti-L12-1 antibody $(1 \mathrm{\mu g} / \mathrm{mL})$. (Bottom) Knockdown of Bcl2L12 in U87MG glioma cells resulted in enhanced sensitivity to STS-induced apoptosis as measured by DNA fragmentation. Depicted is the mean of three independent experiments $(n=3)$ performed in duplicate. Error bars represent standard deviations across all experiments. Comparable results were obtained in three additional GBM cell lines (LN443, LN382, and LNZ308) (data not shown). To assess the statistical significance across all experiments, we also calculated $p$ values for one concentration (1 $\mu$ M STS) for all cell lines tested. Specifically, we "normalized" all siL12-1 and siL12-2 data points to siNT controls at $1 \mu \mathrm{M}$ STS concentration by dividing the mean of all data points for siL12-1 and siL12-2 by the means of siNT yielding fold increase in DNA fragmentation (sensitization index) for each cell line. In this manner, we accounted for baseline cell linespecific apoptosis sensitivities. At $1 \mu \mathrm{M}$ STS, the sensitization indices thus calculated are (Mean \pm SD) $1.51 \pm 0.45$ with $p=0.01$ for siL12-1 and $1.66 \pm 0.46$ with $p=0.003$ for siL12-2 $(n=7)$. (E) Stable knockdown of Bcl2L12 in U87MG glioma cells by two independent shRNAs (shL12-1 and shL12-2) relative to nontargeting control (shNT) was documented by Western blot analysis using the anti-L12-1 antibody $(1 \mathrm{\mu g} / \mathrm{mL})$. (F) Stable knockdown of Bcl2L12 reduces subcutaneous tumor formation $(n=8)$ by U87MG cells in SCID mice. $(G)$ Stable knockdown of Bcl2L12 increased survival of SCID animals $(n=5)$ after intracranial injection of U87MG glioma cells. (H) Resultant tumors showed enhanced apoptosis as measured by the fraction of TUNEL-positive nuclei (700 nuclei were counted per tumor section). Detailed histology on intracranial tumors (see Supplementary Fig. S3) was performed on an independent cohort of animals. All experiments were performed in duplicate or triplicate; error bars represent standard deviations of replicate data points, and two-tailed $p$ values were calculated using the Student's $t$-test.

was assessed in tumorigenesis assays using the wellestablished U87MG human glioma model system. Upon documented $40 \%-60 \%$ knockdown of Bcl2L12 protein level using two independent shRNAs (shL12-1 and shL12-2, respectively) (Fig. 1E), U87MG cells exhibited a threefold sensitization toward STS-induced apoptosis in vitro (data not shown). Importantly, in vivo, such depletion of Bcl2L12 expression resulted in impaired tumorigenicity, as measured by reduced tumor size in subcutaneous xenotransplants (Fig. $1 F)(n=8 ; p=0.00034$ for shNT vs. shL12-1; $p=0.00084$ for shNT vs. shL12-2) and prolonged survival following intracerebral orthotopic injection (Fig. 1G) $(n=5 ; p<0.05)$. Mirroring this decreased tumorigenic potential, the resultant Bcl2L12 knockdown tumors exhibited a marked increase in apoptosis (TUNEL) (Fig. 1H; see also Supplementary Fig. S3) $(p=0.00023$ for shNT vs. shL12-1; $p=0.0017$ for $\operatorname{shNT}$ vs. shL12-2) and a modest decrease in proliferation (BrdU) (data not shown) relative to a nontargeting shRNA control as quantified by counting TUNEL- and BrdU-positive tumor cells per HPF in brain tissue sections. Of particular relevance to the mechanistic studies detailed below, Bcl2L12-knockdown tumors exhibited increased immunoreactivity to active caspase- 7 and caspase-3 (Supplementary Fig. S3), suggesting that tumorigenicity conferred by Bcl2L12 overexpression may relate to its ability to block apoptosis via inhibition of effector caspase activities.

\section{Bcl2L12 inhibits apoptosis signaling downstream from mitochondria}

As a first step in defining Bcl2L12's mechanism of action in apoptosis signaling, we determined its subcellular dis- 
tribution using a polyclonal anti-Bcl2L12 serum (antiL12-2). The specificity of this anti-L12-2 serum was supported by a lack of Bcl2L12 signal detection using preimmune serum, the ability to abolish the Bcl2L12 signal with peptide block (data not shown), and loss of strong Bcl2L12 immunoreactivity in GBM cells infected with a Bcl2L12-specific shRNA, shL12-1, relative to cells with nontargeting control (shNT) (Supplementary Fig. S4A). In immunofluorescence studies using this specific antiL12-2 antiserum, localization of endogenous Bcl2L12 protein was found to be predominantly cytosolic and nuclear without demonstrable mitochondrial association (Supplementary Fig. S4C,D), which was confirmed by subcellular fractionation study (data not shown). A similar localization pattern was determined for ectopically expressed Bcl2L $12^{\mathrm{V} 5}$ in Ink $4 a /$ Arf-deficient astrocytes using antibody against the V5 epitope tag (Supplementary Fig. S4B).

Given the importance of subcellular localization and translocation during cell death progression of apoptosis signaling molecules in their modus operandi, we further assessed the static and dynamic pattern of Bcl2L12 distribution by deconvolution microscopy using organelle-specific antibodies for mitochondria, Golgi, endosomes, and endoplasmic reticulum. As shown in Supplementary Figure S4, C and D, static antiBcl2L12 signal did not colocalize with these cellular structures. Upon STS treatment, Bcl2L12 subcellular distribution remained predominantly cytoplasmic and nuclear, and was confined to a ring around condensed nuclei of apoptotic cells without exhibiting colocalization with membranous endoplasmic reticulum (ER) structures (Supplementary Fig. S4E).

The nonclassical Bcl-2-related structural features and the lack of detectable mitochondrial localization of Bcl2L12 pointed to novel mechanisms in apoptosis regulation. Previous studies have shown that, shortly after induction of apoptosis, cytochrome $\mathrm{c}$ is released from the mitochondrial intermembrane space due to outer membrane permeabilization; this is then followed by the loss of mitochondrial transmembrane potential $\left(\Delta \Psi_{M}\right)$ (for review, see Ferri and Kroemer 2001). Thus, as a first step in positioning the actions of Bcl2L12 upstream of, at, or downstream from the mitochondria in apoptosis signaling, we assessed the impact of Bcl2L12 overexpression on mitochondrial membrane disintegration in comparison to EGFR ${ }^{\star}$ following exposure to an apoptotic stimulus. Consistent with its previously reported role in activation of upstream survival pathways converging to inhibit cytochrome c redistribution (Nagane et al. 1998), EGFR * overexpression dramatically inhibited cytochrome $\mathrm{c}$ translocation into the cytosolic compartment (Fig. 2A,B) $\left(p<0.05\right.$ comparing pBabe vs. EGFR $\left.{ }^{\star}\right)$, whereas Bcl2L12 overexpression had no impact on the release of cytochrome $\mathrm{c}$ as assessed by immunofluorescence and subcellular fractionation or on the dissipation of the mitochondrial membrane potential (Fig. 2). Taken together, these studies definitively place Bcl2L12's point of action downstream from mitochondria in apoptosis signaling.
Bcl2L12 inhibits post-mitochondrial effector caspase activation

The observation that Bcl2L12 expression did not alter cytochrome c release (Fig. 2) or affect apoptosome formation and activity (data not shown) suggested that the anti-apoptotic actions of Bcl2L12 are positioned downstream from mitochondria. To address this, we examined the impact of Bcl2L12 on post-mitochondrial caspase-9, caspase-3, and caspase-7 maturation.

In Bcl2L12-expressing astrocytes exposed to an apoptotic stimulus, caspase-9 autoprocessing appeared marginally affected, but caspase-7 processing was dramatically inhibited (Fig. 3A). The significant impact on caspase-7 processing was further evidenced by the presence of minimal active caspase-7 subunits in lysates of STS-treated Bcl2L12-expressing astrocytes as detected by an antibody specific for the active caspase species (Fig. 3B). While effector caspase-3 processing was also inhibited by Bcl2L12 overexpression, the inhibition was more moderate (Fig. 3A,B). Such incomplete inhibition of caspase-3 processing could explain the slight reduction in upstream caspase-9 maturation to its p37 intermediate via caspase-3-mediated cleavage at a later stage of apoptosis propagation (Fig. 3B, 16 h; Slee et al. 1999; Fujita et al. 2001). In contrast, EGFR * effectively blocked processing of caspase- 9 and subsequent caspase- 3 and caspase-7 maturation (Fig. 3A,B), consistent with absent cytochrome $c$ translocation into the cytosolic compartment (Fig. 2A). In line with these gain-of-function studies, RNA interference (RNAi)-mediated knockdown of endogenous Bcl2L12 expression in human U87MG glioma cells resulted in enhanced activation of caspase-3 and caspase-7, but did not affect early caspase- 9 maturation (Fig. 3C, $0-8 \mathrm{~h}$ ). As a consequence of the aforementioned caspase-3-mediated feedback mechanism (Slee et al. 1999; Fujita et al. 2001), caspase-9 processing in later phases of apoptosis progression was enhanced (Fig. 3C, 16-24 h).

The Bcl2L12-induced inhibition of effector caspase maturation translated into significant reduction in DEVDase activity (Fig. 3D) ( $p=0.087$ at $10 \mathrm{~h} ; p=0.037$ at $12 \mathrm{~h} ; p=0.029$ at $16 \mathrm{~h} ; p=0.14$ at $24 \mathrm{~h}$ for $1 \mu \mathrm{M} \mathrm{STS}$ ), and decreased pull-down of active caspase- 7 and caspase-3 species upon VAD-fmk ${ }^{\text {biotin }}$-affinity labeling and streptavidin precipitation of active caspase species (Fig. 3E). Moreover, this caspase inhibition profile by Bcl2L12 in murine astrocytes and human glioma cells was further confirmed in a cell-free in vitro system. Here, dATP/cyt c-stimulated cell extracts derived from Bcl2L12-overexpressing astrocytes blocked caspase-3-like activity compared with control (Fig. 3F) ( $p=0.01$ for the 30-min time point). In summary, Bcl2L12 showed predominant inhibition of caspase-7 and, to a lesser extent, caspase-3 activation in vitro and in vivo downstream from caspase-9 processing and mitochondrial membrane changes.

\section{Bcl2L12 enhances cellular necrosis}

Inhibition of caspase activity downstream from mitochondrial dysfunction either by genetic inactivation of 
A

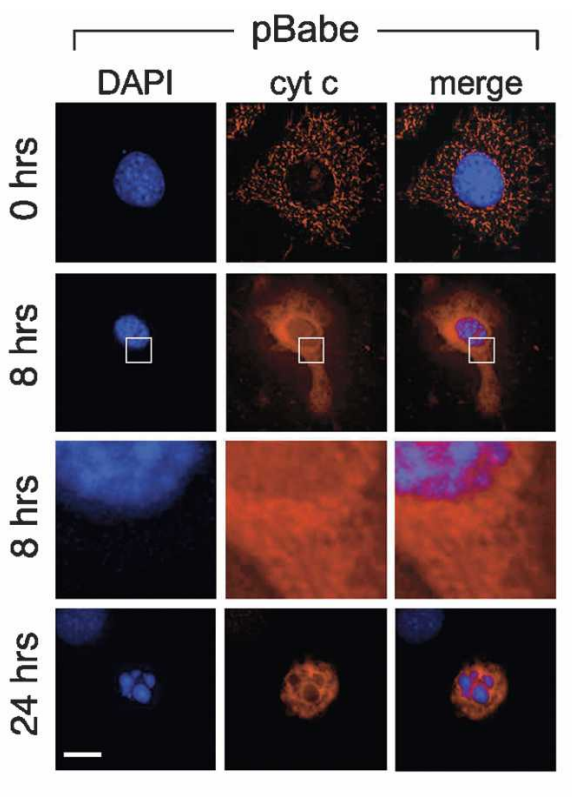

B

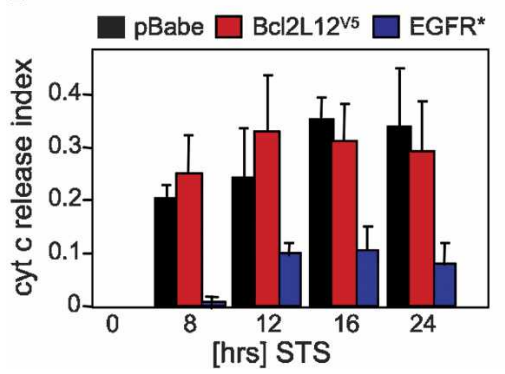

C

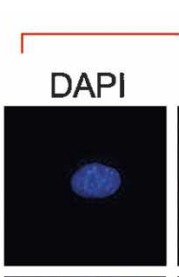

$\mathrm{Bcl} 2 \mathrm{~L} 12^{\mathrm{V} 5}$
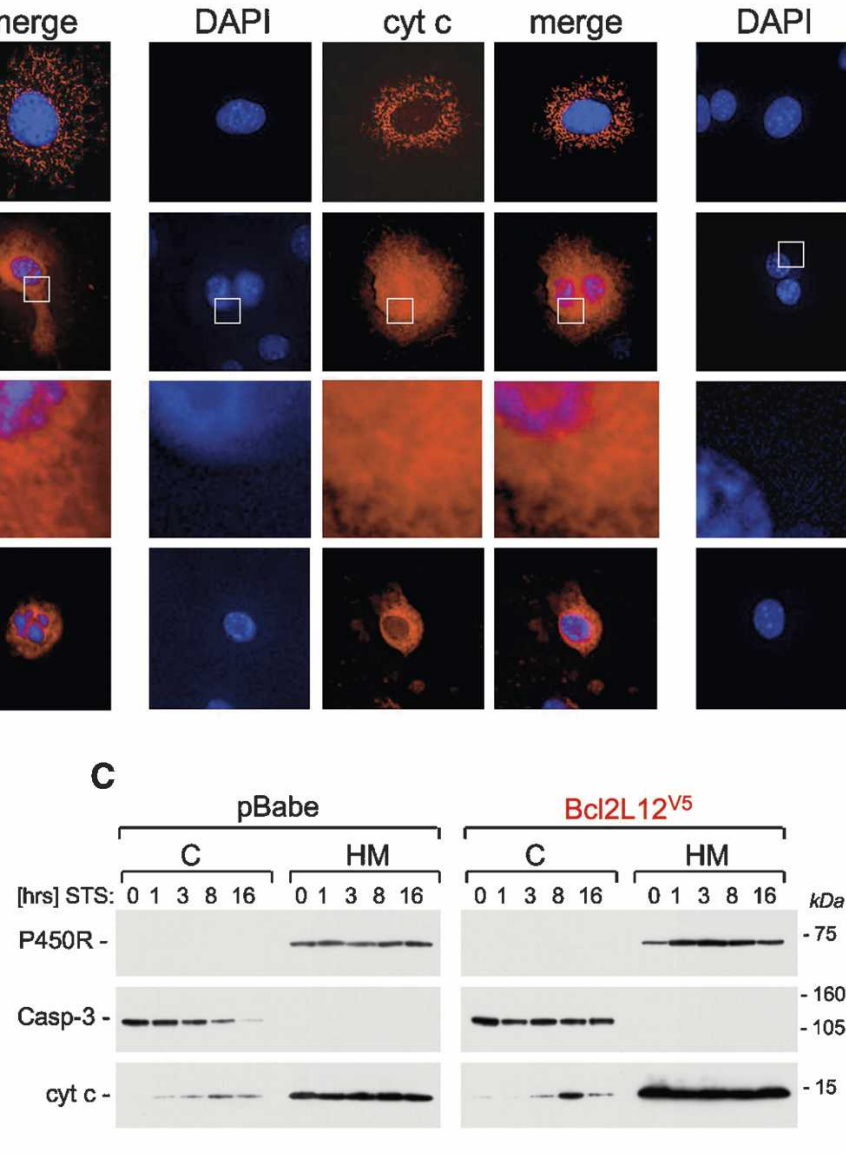

D

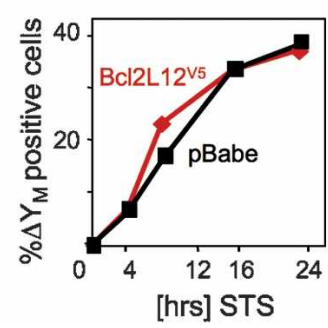

Figure 2. Impact of Bcl2L12 overexpression on mitochondrial integrity following exposure to an apoptotic stimulus. $(A) \mathrm{pBabe-}$ Bcl2L12-, and EGFR*-expressing Ink4a/Arf-deficient astrocytes were treated with $100 \mathrm{nM}$ STS for the indicated periods of time, subjected to immunofluorescence using a monoclonal anti-cytochrome c antibody, and analyzed by deconvolution immunofluorescence microscopy. DAPI, cytochrome c immunofluorescences, and merge images are shown. The framed areas in row 2 were enlarged (row 3 ) to further document diffuse cytochrome c staining in pBabe and Bcl2L12 ${ }^{\mathrm{V} 5}$ astrocytes and preserved mitochondrial cytochrome c localization in EGFR* cultures. $(B)$ Cytochrome c release was quantified by counting cells with diffuse cytosolic cytochrome c staining and presented as a fraction of the total number of cells counted (index). Three HPFs were counted; error bars represent standard deviations, and two-tailed $p$ values were calculated using the Student's $t$-test $\left(p<0.05\right.$ for pBabe vs. EGFR ${ }^{\star}$ at all time points of STS stimulation). (C) Ink4a/Arf ${ }^{-/-}$astrocytes ectopically expressing pBabe or Bcl2L12 ${ }^{\mathrm{v} 5}$ were treated with STS (1 $\left.\mu \mathrm{M}\right)$ for the indicated periods of time. Cytosolic $(\mathrm{C})$ and membranous $(\mathrm{M})$ compartments were isolated and subjected to Western blot analysis to determine cytochrome c distribution. Caspase-3 and cytochrome P450 reductase are shown as marker proteins assessing equal loading and fraction purity. $(D)$ Bcl2L12 does not protect inner mitochondrial membrane integrity. Bcl2L12 ${ }^{\mathrm{V} 5}$ - and pBabe-expressing Ink4a/Arf ${ }^{-/-}$ astrocytes were treated with STS $(1 \mu \mathrm{M})$ for the indicated periods of time, and the mitochondrial transmembrane potential $\left(\Delta \Psi_{M}\right)$ was determined by JC-1 staining and quantified by FACS analysis. The experiment was performed in duplicate, and standard deviations were too small to be depicted.

Apaf-1 (Miyazaki et al. 2001), treatment with caspase inhibitors, or ATP depletion is known to inhibit apoptosis yet provoke cellular necrosis (for review, see Nicotera and Melino 2004; see Discussion). Since Bcl2L12 blocks post-mitochondrial caspase activation, several assays were used to determine whether Bcl2L12 expression caused the necrogenic signatures of nuclear and mitochondrial swelling and plasma membrane disintegration. A combination of Hoechst and SYTOX Green staining was used to assess and quantify plasma membrane integrity. Relative to controls, STS-treated Bcl2L12expressing cultures showed increased SYTOX staining
(Fig. 4A). This loss of plasma membrane integrity typical of necrosis was observed over a range of STS concentrations (Fig. 4B) ( $p=0.0096$ for $0.5 \mu \mathrm{M} ; p=0.0021$ for $2 \mu \mathrm{M}$ STS) and was coincident with a documented reduction in caspase (LEHDase) activity in Bcl2L12-expressing cells relative to controls (Fig. 4B).

Besides disruption of the cytoplasmic membrane, release of nuclear high-mobility group B1 protein (HMGB1) into the cytosol and ultimately into the extracellular environment was shown to be a hallmark of necrosis (Scaffidi et al. 2002). Indeed, upon STS stimulation, antiHMGB1 staining of astrocytic cultures revealed signifi- 
A

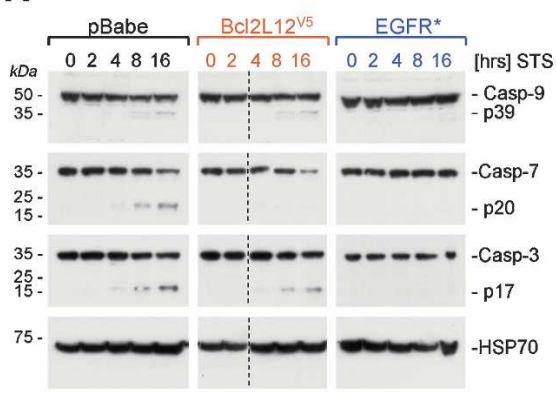

c

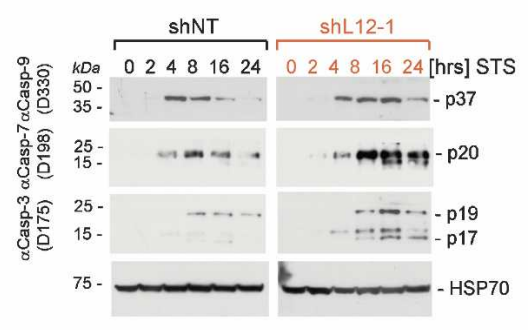

E

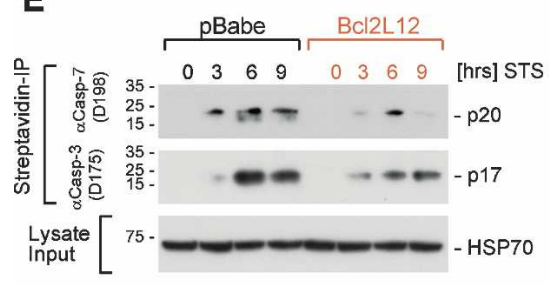

B

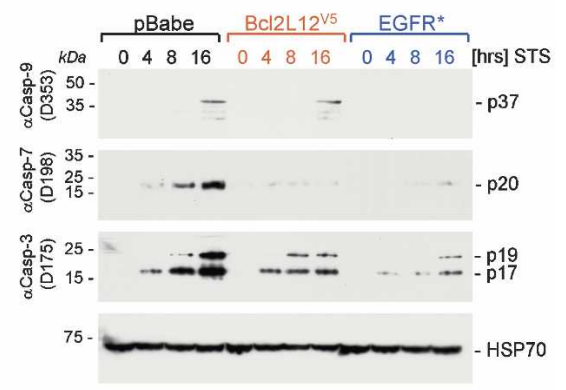

D

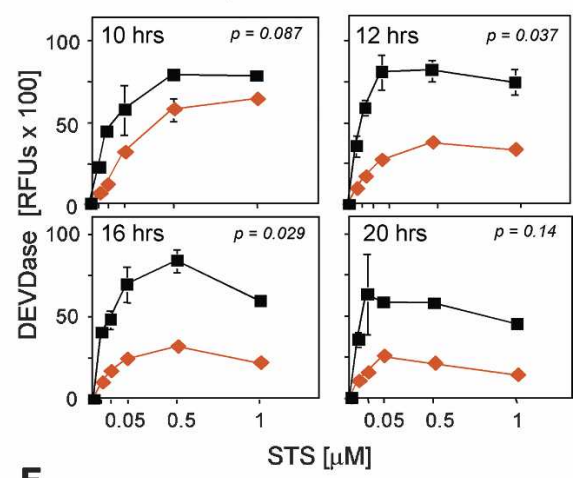

$\mathbf{F}$

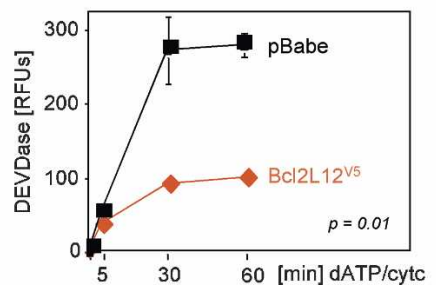

Figure 3. Bcl2L12 inhibits post-mitochondrial effector caspase activity. $(A, B)$ Ink4a/Arf-deficient astrocytic cell cultures ectopically expressing pBabe, Bcl2L12 ${ }^{\mathrm{V}}$, and EGFR ${ }^{\star}$ were treated with STS $(1 \mu \mathrm{M})$ for the indicated periods of time and were subjected to Western blot analyses using antibodies specific for the procaspases $(A)$ and active caspases $(B)$. For $A$, images from two minigels that were blotted onto the same membrane were pasted together: Samples 0, 2, 4, 8, and 16 (pBabe), and 0 and 2 (Bcl2L12) were loaded on one gel, and samples 4, 8, and 16 (Bcl2L12), and 0, 2, 4, 8, and 16 (EGFR *) were loaded on a second gel. We added a dashed line to indicate this. Comparable results were obtained using a STS concentration of $100 \mathrm{nM}$ (data not shown). (C) U87MG cells stably expressing a nontargeting control (shNT) or a Bcl2L12-specific shRNA (shL12-1) were treated with STS (1 $\mu M)$ for the indicated periods of time, lysed, and subjected to Western blot analysis as in B. (D) Ink4a/Arf-deficient astrocytic cell cultures ectopically expressing pBabe or Bcl2L12 ${ }^{\mathrm{V} 5}$ were treated with the indicated doses of STS and were assayed for DEVDase activity at 10,12, 16, and 20 $\mathrm{h}$ using an AFC-labeled DEVD peptide. $P$ values were calculated for the $1 \mu \mathrm{M}$ doses. (E) pBabe- and Bcl2L12-expressing astrocytes were treated with STS $(1 \mu \mathrm{M})$ for the indicated periods of time and lysed, and active caspases were affinity-labeled with biotinylated VAD-fmk. Streptavidin precipitates were analyzed by Western blot using antibodies specific for active caspase-3 and caspase-7. (F) Lysates from pBabe- and Bcl2L12-expressing astrocyte cultures were activated with dATP (1 mM) and cytochrome c $(5 \mu \mathrm{M})$, and DEVDase activity was monitored using AFC-labeled DEVD peptide. The $p$ value was calculated for the 60-min time point. Error bars represent standard deviations of replicate data points, and two-tailed $p$ values were calculated using the Student's $t$-test.

cant release of HMGB1 from the nuclei of Bcl2L12expressing astrocytes into the cytosol, whereas it remained sequestered in the nuclei of pBabe-infected control cultures (Fig. 4C, 16-h time point). Quantification of HMGB1 cytosolic staining over a 24-h period showed that HMGB1 release was significantly more robust in Bcl2L12-expressing astrocytes relative to pBabe controls (Fig. 4D) ( $p=0.009$ and $p=0.008$ at $16-$ and 24 -h time points, respectively).

Finally, in transmission electron microscopy studies, STS-treated pBabe control cultures exhibited the classical chromatin condensation and preservation of submitochondrial structures typical of an active apoptosis process (Fig. 4E). In contrast, Bcl2L12-expressing cultures possessed large nuclei without significant signs of condensed chromatin and mitochondria with pale matrix and annihilated crystae (Fig. 4E). Together, these various experimental assays documented that, in astrocytes, Bcl2L12 expression can promote necrotic cell death in response to apoptotic stimulation.

\section{Bcl2L12 physically interacts with caspase-7}

Next, to define further the molecular actions of Bcl2L12, we assessed its physical interactions with key postmitochondrial apoptosis signaling molecules. AntiBcl2L12 immunoprecipitates from the glioma cell lines LNZ308 and U87MG as well as the embryonic kidney cell line 293T revealed the presence of significant amounts of endogenous procaspase-7, but not procaspase-3 (Fig. 5A). Conversely, Bcl2L12 knockdown resulted in a significant decrease in coimmunoprecipitated procaspase-7 (Fig. 5B). In line with these immunoprecipitation (IP) results, prominent colocalization of Bcl2L12 and caspase-7 was observed in nuclear and granular cytosolic structures (Fig. 5C, left panel)-a distribution pattern also exhibited by XIAP (Fig. 5C, right panel), a known caspase-7 inhibitor. In addition, in vitro pulldown assays using GST or GST-Bcl2L12 confirmed substantial association with in vitro translated caspase-7 and $\Delta$ N-caspase-7 (Fig. 5D, lanes 10,11), whereas 
Figure 4. Bcl2L12 promotes necrosis. $(A)$ pBabe- or Bcl2L12-expressing Ink4a/Arf ${ }^{-1}$ astrocyte cultures were treated with STS $(2 \mu \mathrm{M})$ for $20 \mathrm{~h}$ prior to staining with a combination of Hoechst 33342 and SYTOX Green, a green fluorescent dye staining necrotic cells with a disintegrated plasma membrane. The percentage of the necrotic population was determined by FACS. $(B)$ pBabe- or Bcl2L12-expressing Ink4a/Arfdeficient astrocytes were treated with the indicated amounts of STS, and SYTOX-Green positivity as well as relative LEHDase activity (indicated as relative fluorescence units, RFUs) was assessed. Approximately 100 cells per HPF (total of three HPFs) were counted for each data point and the necrotic index was calculated as the fraction of cells positive for SYTOX green divided by the total number of cells counted. Error bars represent standard deviations of replicate data points, and two-tailed $p$ values were calculated using the Student's $t$-test. $(C)$ pBabe- or Bcl2L12-expressing Ink4a/Arf ${ }^{-1-}$ astrocyte cultures were incubated for the indicated periods of time with $1 \mu \mathrm{M}$ STS, and subjected to anti-HMGB1 staining using a polyclonal anti-HMGB1 antibody. Representative pictures of DAPI, anti-HMGB1, and merged immunofluorescences are shown. White arrowheads point to a secondary necrotic cell. Of note, all HMGB1 immunfluoresence images were taken at the same magnification. The apparent large size of STS-treated Bcl2L12 astrocytes reflects the fact that these cells are necrotic with swollen nuclei and extended cytoplasms. Bar, $15 \mu \mathrm{m}$. (D) Quantitation of HMBG1 cytosolic staining of cultures from $C$ over a 24 -h period by counting numbers of HMBG1-positive cells per HPF (total of three HPFs counted per time point). Cells with released HMGB1 were divided by the total number of cells counted and expressed as an HMBG1 release index. Error bars represent standard deviations of replicate data points, and two-tailed $p$ values were calculated using the Student's $t$-test. $(E)$ pBabe- or Bcl2L12 ${ }^{\mathrm{V} 5}$ expressing Ink4a/Arf-deficient astrocytes were incubated with STS $(1 \mu \mathrm{M})$ for the indicated periods of time, and cellular morphology (left) as well as mitochondrial ultrastructure (right) were analyzed by transmission electron microscopy.

caspase-9 failed to show in vitro complex formation with recombinant Bcl2L12 (Fig. 5D, lanes 9,11). Furthermore, when incubated with active caspase-7 subunits (generated by recombinant caspase-3-mediated proteolysis of in vitro translated procaspase-7), GST-Bcl2L12 was found to bind to the large and small active subunits (LS and SS) more efficiently when compared with full-length caspase-7 species (Fig. 5D, lane 12). This interaction is mediated through direct protein-protein interaction, since recombinant GST-Bcl2L12 directly bound recombinant soluble (His) ${ }_{6}$-tagged caspase- 7 as documented by substantial pull-down of the large active caspase-7 subunit with GST-Bcl2L12 (Fig. 5E, lane 12). This inter- action matches well with Bcl2L12's ability to inhibit caspase- 7 maturation induced by addition of dATP/cytc or recombinant active caspase-3 (Fig. 5F; data not shown).

In agreement with concomitant albeit less significant inhibition of caspase-3 processing in STS-treated Bcl2L12-expressing astrocytes (Fig. 3A,B), caspase-3 processing was also blocked in $\mathrm{dATP} / \mathrm{cyt}$ c-stimulated lysates in the presence of Bcl2L12 in a cell-free system (A.H. Stegh and R.A. DePinho, unpubl.), consistent with dual effector caspase inhibition. Thus, we propose that Bcl2L12 inhibits caspase-7 maturation through direct protein-protein interaction. In contrast, since physical 

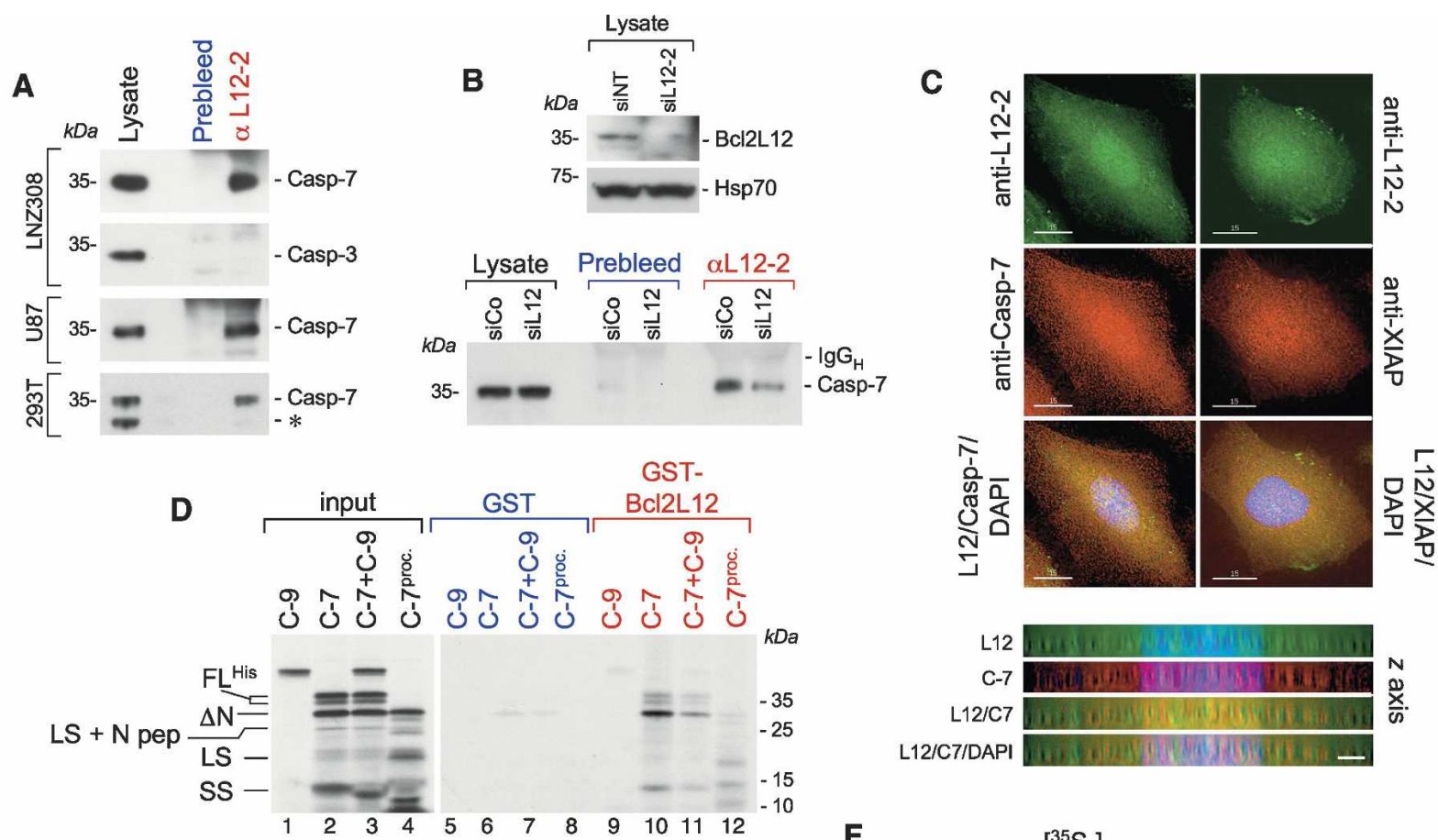
$\mathrm{Da}$

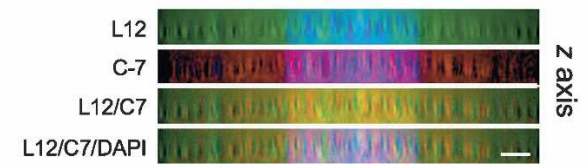

E

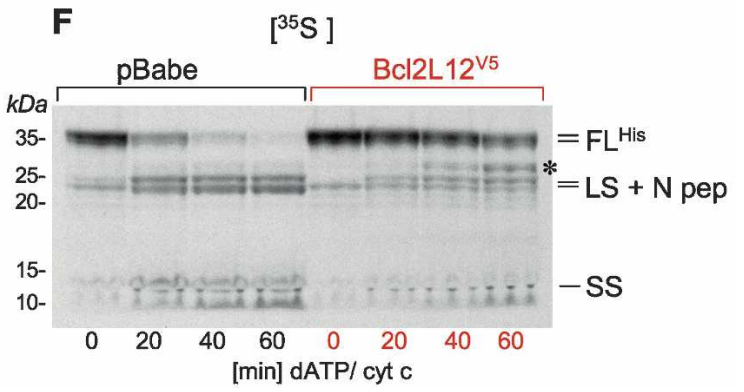

Figure 5. Bcl2L12 directly interacts with caspase-7 in vitro and in vivo. (A) Anti-L12-2 immunoprecipitates from lysates of LNZ308, U87MG, and 293T cells were subjected to Western blot analysis for procaspase-7 and procaspase-3. For the lysate lane, one-fortieth of the lysate used for the IP was loaded. The asterisk-marked band in the lysates of 293T cells most likely represents an N-terminally truncated caspase-7 enzyme. (B, top) Anti-L12-2 immunoprecipitates from siNT- and siL12-2-transfected U87MG cells with documented knockdown of Bcl2L12 by Western blot were subjected to Western blot analysis for caspase-7. As in $A$, one-fortieth of the lysate was loaded in the lysate lanes. Hsp70 is shown as a loading control for the Bcl2L12 Western blot. (C) LNZ308 cells were subjected to deconvolution microscopy using the anti-L12-2 antiserum (top row), a monoclonal anti-caspase-7 antibody (left panel, center row), and a monoclonal anti-XIAP antibody (right panel, center row). (Bottom row) Green and red images were overlaid together with DAPI stainings. Bar, $15 \mu \mathrm{m}$. (Bottom panel) Deconvoluted images for the Bcl2L12/caspase-7 staining were rotated by $90^{\circ}$ along the $X$-axis to analyze Bcl2L12 and caspase-7 distribution along the $Z$-axis. Bar, $3 \mu \mathrm{m}$. $(D)$ In vitro translated caspase-9 (C-9), caspase-7 (C-7) with a C-terminal His-tag, a mixture of caspase-9 and caspase-7 (C-9 + C-7), and processed caspase-7 (in vitro translated caspase-7 preincubated with $2.8 \mathrm{nM}$ recombinant active caspase-3) were incubated with GST or GST-Bcl2L12 coupled to GSH beads. Precipitates were subjected to SDS-PAGE followed by autoradiography. The migration positions of caspase-7 and of the active caspase-7 subunits are indicated. (FL $\left.{ }^{\mathrm{His}}\right)(\mathrm{His})_{6}$-tagged full-length caspase-7; (LS) large subunit; (SS) small subunit; (N pep) N-terminal peptide spanning amino acids 1-23. (E) GST or GST-Bcl2L12 was incubated with increasing amounts of soluble recombinant (His) ${ }_{6}$-tagged caspase-7, and subjected to SDS-PAGE followed by Coomassie staining or by Western blot analysis using an anti-caspase-7 antibody. (Lanes 1-3) Due to immediate autoproteolysis of procaspase-7 upon protein induction in bacteria (Stennicke and Salvesen 1999), the proenzyme was nearly completely converted into cleavage intermediates. The migration positions of the caspase-7 species are indicated. $(F)$ Lysates from pBabe- and Bcl2L12-expressing astrocyte cultures were activated with dATP $(1 \mathrm{mM})$ and cytochrome $\mathrm{c}(5 \mu \mathrm{M})$, and the processing of in vitro translated caspase-7 was followed by autoradiography. Of note, an in vitro translated band at $\sim 32 \mathrm{kDa}$ accumulated in stimulated Bcl2L12 lysates (marked with an asterisk) that could possibly represent $\Delta \mathrm{N}$-caspase-7, which has been shown to only have minor catalytic (DEVDase) activity (Denault et al. 2006).

interaction between Bcl2L12 and caspase-3 could not be demonstrated (Fig. 5A), Bcl2L12 likely regulates caspase-3 activity via a different mechanism (see Discussion).

The Bcl2L12-caspase-7 interaction prompted a more direct analysis of relevance of caspase-7 role in governing apoptosis/necrosis processes in astrocytes. Similar to overexpression of Bcl2L12, RNAi-mediated knockdown of caspase-7 (Supplementary Fig. S5A) provoked a pro- 
found anti-apoptotic and pronecrotic response characterized by plasma membrane disintegration and absent chromatin condensation (Supplementary Fig. S5B). Quantification of apoptotic and necrotic cells using chromatin condensation and plasma membrane integrity as the two major hallmarks of these forms of cell death revealed a lower apoptotic and a higher necrotic index in siRNA-Casp-7-treated astrocytes, similar to the cellular phenotype of Bcl2L12 overexpression (Supplementaty Fig. S5B,C). It is worth noting that, in contrast to ectopic expression of Bcl2L12, knockdown of caspase-7 did not affect caspase-3 processing (data not shown) and had a significant, but only moderate effect on DNA fragmentation at lower STS doses (percent DNA fragmentation \pm SD: Control NT siRNA $46.7 \pm 0.43 \%$, Casp-7 siRNA SMARTPool $30.2 \pm 5.6 \%$; $p=0.028$ ), raising the possibility that additional Bcl2L12 activities may be operative to indirectly neutralize caspase- 3 in order to more completely shut down effector caspase activity (see Discussion).

\section{Discussion}

In this study, we provide physical and functional evidence that Bcl2L12 functions as a novel anti-apoptotic protein in primary astrocytes and glioma cells. Bcl2L12 acts downstream from mitochondria at the level of effector caspases through direct physical interaction with caspase-7. Consistent with its post-mitochondrial actions, Bcl2L12 confers apoptosis resistance to diverse agents and stimulates a necrogenic response. On the basis of these biological and biochemical activities, together with frequent and robust expression in human primary GBM specimens, we propose that Bcl2L12 is an important contributor to two patho-physiological characteristics of human GBM, namely, therapeutic resistance and necrosis.

Mechanistically, in astrocytes and glioma cells, Bcl2L12 did not exhibit "classical" anti-apoptotic Bcl-2like activities of inducible or constitutive mitochondrial localization and thus failed to protect outer or inner membrane integrity as evidenced by a detailed examination of the biphasic kinetics of mitochondrial membrane disruption. Specifically, Bcl2L12 did not inhibit cytochrome c release (disruption of the outer leaflet) or subsequent caspase-dependent $\Delta \Psi_{M}$ dissipation (an indicator of inner mitochondrial membrane integrity). This profile, coupled with normal caspase-9 activation yet inhibition of DNA fragmentation and apoptotic morphology, is consistent with Bcl2L12's ability to interfere with maturation of the effector caspases. Interestingly, Bcl2L12 appears to regulate caspase- 3 and caspase-7 activities via different mechanisms. Bcl2L12 potently inhibits caspase-7 maturation, most likely through direct physical interaction, suggesting that caspase- 7 is the key target of Bcl2L12 actions in glial cells. In this light, it is worth noting that caspase-7, as opposed to caspase-3, appears to be the key effector caspase during IFN- $\beta-$, cytotoxic drug-, and Bcl-2/Bcl- $\mathrm{x}_{\mathrm{L}}$ antisense-induced apoptosis in glioma cell lines (Glaser and Weller 2001; Jiang et al.
2003; Saito et al. 2004). In addition, caspase-7 deficiency in DT40 cells has been shown to result in increased resistance toward drug-induced apoptosis as a consequence of reduced and delayed caspase activity, positioning caspase-7 as a central executioner caspase (Korfali et al. 2004). Mouse embryonic fibroblasts, murine T or B cells, and hepatocytes deficient in caspase-7, however, exhibit only a slight or no survival advantage when treated with apoptosis inducers (Lakhani et al. 2006), suggesting that cell type is a major factor that dictates the prominence of caspase-7 in cell death propagation (Zheng et al. 2000; Houde et al. 2004). Indeed, consistent with a central role for caspase- 7 in post-mitochondrial death propagation in glioma cells, we observe that caspase-7 knockdown provokes an anti-apoptotic and pronecrotic response (Supplementary Fig. S5). Such observations reinforce the views that caspase- 7 is relevant to the apoptosis/necrosis balance in glioma cells and that caspase-7 neutralization is at least one vital aspect of Bcl2L12's overall anti-apoptotic and pronecrotic activity.

Bc12L12 also modulated caspase-3 activities in astrocytes and glioma cells, albeit to a lesser extent than caspase-7. The mechanistic basis for the modest regulation of caspase-3 is not fully understood at present. While Bcl2L12 does not physically interact with caspase3 , preliminary transcriptome analysis has revealed marked up-regulation of $\alpha \mathrm{B}$-crystallin in Bcl2L12-overexpressing astrocytes (A.H. Stegh and R.A. DePinho, unpubl.). This observation gains added significance in light of the capacity of $\alpha \mathrm{B}$-crystallin to selectively bind and inhibit caspase-3 (Kamradt et al. 2001, 2005; Moyano et al. 2006). In addition, $\alpha$ B-crystallin exhibits frequent overexpression in GBM (Aoyama et al. 1993; Kato et al. 1993; Hitotsumatsu et al. 1996; A.H. Stegh and R.A. DePinho, unpubl.). Thus, Bcl2L12 is a multifunctional protein that inhibits post-mitochondrial caspase signaling in astrocytes and glioma cells at the level of caspase-7 processing likely through direct protein-protein interaction, and at the level of caspase- 3 maturation, possibly through indirect up-regulation of $\alpha \mathrm{B}$-crystallin. Together, these dual mechanisms are reminiscent of IAP proteins, which interact with and inhibit multiple postmitochondrial caspases (Vaux and Silke 2005).

With respect to differential prominence of Bcl2L12 across different cell types, it is worth noting that several studies suggest a role for cellular context in dictating whether Bcl2L12 promotes or suppresses tumorigenesis. For example, Bcl2L12 overexpression in mammary tumors has been correlated with improved disease-free and overall survival (Talieri et al. 2003; Thomadaki et al. 2006), while Bcl2L12 expression, in particular, expression of a shorter isoform Bcl2L12-A, was associated with tumor progression and poor prognosis in colon cancer (Mathioudaki et al. 2004). These data suggest contextspecific functions of Bcl2L12, an increasingly common profile for many cancer-relevant proteins whose contrasting activities are strongly influenced by cellular, physiological, and/or genotypic context, as reported for c-Myc (for review, see Pelengaris et al. 2002), and possibly Bcl-2 (e.g., see Lin et al. 2004). 
Consistent with the central observations of this study, there is increasing recognition that post-mitochondrial caspase activation can act as a molecular switch between apoptotic and necrotic cell death (for review, see Nicotera and Melino 2004). For example, sufficiently low levels of intracellular ATP can block Apaf-1/ATP-mediated activation of downstream caspases upon apoptosis induction, leading to loss of typical apoptotic features and acquisition of a necrotic profile in dying cells (Leist et al. 1997). Consistent with that, Apaf-1 deficiency and/or blockage of effector caspases indeed provoke a necrotic response to apoptosis initiation (Miyazaki et al. 2001), similar to Bcl2L12-mediated inhibition of caspase-3 and caspase-7 shown here. Thus, in the context of GBM, we propose that the biological and biochemical properties of Bcl2L12 contribute to the unusual tumor biological features of intense apoptosis resistance and extensive necrosis. At the same time, we acknowledge that other molecular factors also fuel necrosis: vascular occlusion as a possible consequence of endothelial apoptosis is often associated with intravascular thrombosis. Particularly, hyperactive receptor tyrosine kinase signaling and subsequent activation of the Ras-MAPK (mitogenactivated protein kinase) pathway within neoplastic tissue are known to cause NF-кB-mediated up-regulation of $\mathrm{TNF} \alpha$ that in turn initiates a tissue factor-mediated coagulation cascade resulting in elevated fibrin deposition and microthrombosis (for review, see Raza et al. 2002). The decreased perfusion within the vascular network and associated hypoxia and glucose deprivation avert glycolysis and block oxidative phosphorylation leading to energy depletion and dysregulated cellular homeostasis (for review, see Raza et al. 2002; Zong and Thompson 2006).

The pronecrotic activity of $\mathrm{Bcl} 2 \mathrm{~L} 12$ in response to apoptotic stimulation provides molecular support for the emerging concept that apoptosis and nonapoptotic death paradigms are intertwined. As a consequence of its postmitochondrial modus operandi, Bcl2L12 represents a prototypic protein that could promote necrogenesis and inhibit apoptosis through its actions on effector caspase activity downstream from mitochondrial dysfunction. Along this line, it is tempting to speculate that necrosis is a tumor suppressor mechanism: Recent evidence suggests that a variety of intracellular proteins are released during necrotic cell death-including hepatoma-derived growth factor (HDGF) - that not only induce a proinflammatory response but may also promote tumor growth and invasion (Zhou et al. 2004; Zhang et al. 2006). However, it is also clear that, despite this cellular phenotype of necrosis, Bcl2L12 may confer net tumorigenic activity that likely stems from its overriding capacity to block apoptosis under appropriate genetic context and/or additional activities affecting other cancerrelevant processes such as cell proliferation. This profile of contrasting activities is reminiscent of oncogenes such as Myc, which can enhance proliferation yet sensitize cells to apoptosis depending on genetic and physiological contexts (Pelengaris et al. 2002).

Antagonizing inhibitors of effector caspases was re- cently shown to be an effective and promising anti-oncologic therapeutic strategy. In particular, small-molecule neutralization of XIAP-mediated inhibition of caspase-3 and caspase-7 induced apoptosis in many tumor cell lines with little toxicity in normal tissue; this approach was shown to sensitize cancer cells toward chemotherapy and suppress tumor explant growth in vivo (Schimmer et al. 2004). In the light of Bcl2L12's impact on effector caspase function through direct physical interaction and the low-level expression of Bcl2L12 in the adult brain, we propose that pharmacological neutralization of Bcl2L12's anti-apoptotic activities provides a strategic point of therapeutic intervention for GBM due to its IAP-like caspase inhibitory activity at a very distal end of the apoptotic signaling pathway.

\section{Materials and methods}

\section{Cloning of Bcl2L12}

Bcl2L12 cDNA was isolated by RT-PCR from total RNA that was prepared from total normal cortical brain tissue and cloned into pcDNA3.1V5/His (Invitrogen).

\section{Astrocyte preparation and retrovirus production}

Primary cortical astrocytes were isolated from 5-d-old pups and prepared according to published methods (McCarthy and de Vellis 1980). Cells were maintained in Dulbecco's modified Eagle medium (DMEM) containing 10\% fetal bovine serum (FBS; GIBCO). For the production of retroviral stocks, subconfluent $293 \mathrm{~T}$ cells were plated onto $10-\mathrm{cm}$ dishes $14-18 \mathrm{~h}$ before transfection with pBabe, pBabe-Bcl2L12 ${ }^{\mathrm{v} 5}$, and pBabe-EGFR ${ }^{\star}$ along with pCL (Naviaux et al. 1996). Transfection by Lipofectamine Plus (Invitrogen) was performed according to the manufacturer's protocol. The retroviral supernatant was harvested $36-48 \mathrm{~h}$ post-transfection and was used to infect target cells. Inoculated cells were selected with $2 \mu \mathrm{g} / \mathrm{mL}$ puromycin for $4 \mathrm{~d}$.

\section{Generation of two rabbit polyclonal anti-Bcl2L12 antisera}

The peptides CWRRPQVEWRRRRWGP (for anti-L12-1) and CSRDDSSRPSRAAPG (for anti-L12-2) that correspond to amino acids 65-79 and 254-268 were used for immunization of rabbits (Zymed Laboratories). Cys266 was substituted by Ala to prevent disulfide bridging, and the first Cys residue was used to form single-point, site-directed conjugation to KLH. Rabbits were immunized four times, and serum specificity was first tested by ELISA against the synthetic peptide. The anti-L12-1 antiserum was further affinity-purified.

GST-Bcl2L12 and (His) ${ }_{6}$-caspase-7 recombinant protein isolation, IP, and Western blotting

For isolation of recombinant proteins, BL21 bacteria were induced with IPTG (Sigma) for $6 \mathrm{~h}$ at a concentration of $1 \mu \mathrm{M}$ (GST-Bcl2L12) or for $10 \mathrm{~min}$ at a concentration of $0.2 \mu \mathrm{M}$ $\left[(\mathrm{His})_{6}\right.$-caspase-7]. Cells were lysed in Bac-Buffer $(20 \mathrm{mM}$ Tris$\mathrm{HCl}$ at $\mathrm{pH} 8.0,500 \mathrm{mM} \mathrm{NaCl}, 10 \%$ glycerol, $1 \%$ Triton $\mathrm{X}-100$, protease inhibitor cocktail [Roche]) and subsequently sonified for $1 \mathrm{~min}$. Lysates were cleared by centrifugation $(5000 \times \mathrm{g})$ and incubated with GSH-Sepharose 4B (Amersham) or Ni-NTA agarose (Qiagen) for $2 \mathrm{~h}$ at $4^{\circ} \mathrm{C}$. If needed, $(\mathrm{His})_{6}{ }_{6}$-caspase- 7 was 
eluted by incubating beads with $500 \mathrm{mM}$ imidazol in $20 \mathrm{mM}$ phosphate buffer/0.5 M NaCl (Amersham).

For pull-down experiments using GST-Bcl2L12 or (His) ${ }_{6}$ caspase-7, fusion proteins were preincubated in IP buffer (142 $\mathrm{mM} \mathrm{KCl}, 5 \mathrm{mM} \mathrm{MgCl} 2,10 \mathrm{mM}$ HEPES-KOH at $\mathrm{pH} 7.2,1 \mathrm{mM}$ EDTA, $0.4 \%$ NP-40, protease inhibitor cocktail [Roche]) containing $0.1 \%$ BSA to block unspecific binding. Using a TNTcoupled reticulocyte lysate system (Promega), Bcl2L12 ${ }^{\mathrm{V} 5}$, caspase-7, and caspase-9 were in vitro translated in the presence of $\left[{ }^{35} \mathrm{~S}\right]$ methionine, and in vitro translated proteins were incubated with $1 \mu \mathrm{g}$ of recombinant fusion proteins precoupled to GSH or Ni-NTA beads for $2 \mathrm{~h}$ at $4^{\circ} \mathrm{C}$ in IP buffer. Subsequently, beads were washed three times with IP buffer, and associated proteins were analyzed by $4 \%-12 \%$ SDS-PAGE followed by autoradiography. For in vitro processing of caspase-7, $2.8 \mathrm{nM}$ recombinant active caspase-3 (Pharmingen) was added to $\left[{ }^{35} \mathrm{~S}\right]$ radiolabeled caspase- 7 for $2 \mathrm{~h}$ at $37^{\circ} \mathrm{C}$ in assay buffer $(20 \mathrm{mM}$ HEPES-KOH, $100 \mathrm{mM} \mathrm{NaCl}, 0.1 \%$ CHAPS, $10 \%$ sucrose, 10 mM DTT).

For IPs using the anti-L12-2 antiserum, $6 \times 10^{6}$ LNZ308 and U87MG cells or $10^{6} 293 \mathrm{~T}$ cells were lysed in IP buffer. Cleared supernatants were incubated with prebleed serum $(8 \mu \mathrm{L})$ coupled to Protein A-Sepharose 4B beads (Sigma) for $1 \mathrm{~h}$, and subsequently with anti-L12-2 antiserum $(8 \mu \mathrm{L})$ for $1-2 \mathrm{~h}$.

For all Western blot analyses, proteins were separated by $4 \%-$ $12 \%$ SDS-PAGE, transferred to Hybond PVDF membranes (Amersham), blocked with $5 \%$ milk in phosphate-buffered saline with $0.05 \%$ Tween 20 (PBS/Tween) for $1 \mathrm{~h}$, washed with PBS/Tween, and incubated with the following antibodies: anticytochrome c $(0.5 \mu \mathrm{g} / \mathrm{mL}$; BD Pharmingen), anti-cytochrome P450 reductase $(0.2 \mu \mathrm{g} / \mathrm{mL}$; Santa Cruz Biotechnologies), anticaspase-7 (0.5 $\mu \mathrm{g} / \mathrm{mL}$; BD Pharmingen), anti-caspase-3 (0.25 $\mu \mathrm{g} /$ $\mathrm{mL}$; BD Transduction Laboratories), anti-cleaved Caspase-3 (1:1000; Calbiochem), anti-cleaved Caspase-9 D315 and D330 (1:1000; Calbiochem), anti-Caspase-9 specific for mouse procaspase-9 (1:1000; Cell Signaling), anti-cleaved caspase-9 specific for mouse (1:1000; Cell Signaling), anti-cleaved Capase-7 (1:1000; Calbiochem), anti-Hsp70 and Hsp90 (1:4000; BD Pharmingen), anti-L12-1 (1 $\mu \mathrm{g} / \mathrm{mL})$, and anti-L12-2 (1:6000) in 5\% milk in PBS/Tween 20. The blots were washed with PBS/Tween and developed with goat anti-rabbit $\operatorname{IgG}(1: 10,000)$ or with goat anti-mouse antibodies (1:10,000; Pierce) in $5 \%$ milk PBS/ Tween. After washing with PBS/Tween, the blots were developed with the Lumigen PS3 kit (Amersham) following the manufacturer's protocol.

\section{siRNA transfection and generation of U87MG cells stably expressing shRNAs}

Subconfluent glioma cells were transfected with siRNA oligonucleotides (Dharmacon; siRNA nontargeting control, catalog no. D-001210-01-20), siL12-1 (AAGCUGGUCCGCCUGUCCU), and siL12-2 (UGGUGGAGCUGUUCUGUAG; siCasp-7 Smart Pool, catalog no. L-057362-00), at a concentration of $100 \mathrm{nM}$ using Oligofectamine (Invitrogen). Cells were treated with STS $(0.2-1 \mu \mathrm{M}) 36 \mathrm{~h}$ post-transfection and assayed for DNA fragmentation, caspase maturation, activity, and cytochrome c release. For generation of U87MG cells stably expressing Bcl2L12targeting shRNAs, subconfluent Phoenix cells were transfected with pMD2.G containing VSV-G and the shRNA /GFPControl, shL12-1 and shL12-2, Open Biosystems, catalog no. RHS1764-9192649, RHS1764-921071) in pMSCV-puro-IRESGFP (MSCV-PIG) mated with pMS2 (Open Biosystems; $9 \mu \mathrm{g}$ of shRNA construct $+1 \mu \mathrm{g}$ of pMD2.G-VSV-G). Medium was changed $16 \mathrm{~h}$ post-transfection. Supernatants were harvested $24 \mathrm{~h}$ later, sterile filtered, and added to U87MG cells for $48 \mathrm{~h}$ with polybrene $(5 \mu \mathrm{g} / \mathrm{mL})$. Cells were selected in puromycin $(8$ $\mu \mathrm{g} / \mathrm{mL}$ ) for $4 \mathrm{~d}$.

\section{$R T-q P C R$}

To analyze Bcl2L12 mRNA expression in tumor samples, total RNA was transcribed into cDNA using SuperScript reverse transcriptase (Invitrogen). qPCR was performed by monitoring in real time the increase in fluorescence of SYBR Green dye (Qiagen) with an ABI 7700 (Applied Biosystems) sequence detection system (Perkin-Elmer). The relative expression levels were calculated by the comparative $C t$ method (Ginzinger 2002).

\section{Quantification of apoptosis}

Apoptosis was induced using the pan-specific kinase inhibitor STS (Sigma), TNF $\alpha$ (Sigma) plus cycloheximide $(1 \mu \mathrm{g} / \mathrm{mL}$; Sigma), or $\gamma$-irradiation. For quantification of DNA fragmentation, astrocytes were trypsinized and fixed in ice-cold methanol for 30 min. Cells were washed twice and resuspended in PBS containing $10 \mu \mathrm{g} / \mathrm{mL}$ propidium iodide and $100 \mu \mathrm{g} / \mathrm{mL}$ RNaseA. Glioma cell lines were harvested, washed once with PBS, and resuspended and incubated for at least $2 \mathrm{~h}$ at $4^{\circ} \mathrm{C}$ in Nicolettibuffer $(0.1 \%[\mathrm{w} / \mathrm{v}]$ sodium citrate, $0.1 \%$ [v/v] Triton X-100, 50 $\mathrm{\mu g} / \mathrm{mL}$ propidium iodide). The percentage of DNA fragmentation was assessed by FACS analysis to quantify sub-G1 peaks. For measurement of caspase activity, astrocytes or glioma cells were stimulated with STS and lysed with lysis buffer C (150 $\mathrm{mM} \mathrm{NaCl}, 30 \mathrm{mM}$ Tris- $\mathrm{HCl}$ at $\mathrm{pH} 7.5,10 \%$ glycerol [v/v], 1\% Triton X-100 [v/v], protease inhibitor cocktail [Roche]). The cell lysates were incubated with $40 \mu \mathrm{M}$ amino trifluoromethyl coumarin (AFC)-labeled caspase-specific peptides zDEVD-AFC for caspase-3 and caspase-7 and Ac-LEHD-AFC for caspase-9 (Bachem) in assay buffer and incubated for $0.5-1 \mathrm{~h}$ at $37^{\circ} \mathrm{C}$. Caspase activities were determined fluorometrically using a fluorescence plate reader. Values obtained with unstimulated cells were taken as background and subtracted from those obtained with stimulated cells. To measure $\Delta \Psi_{\mathrm{M}}$, STS-treated or untreated astrocytes expressing pBabe or Bcl2L12 ${ }^{\mathrm{V} 5}\left(5 \times 10^{5} / \mathrm{mL}\right)$

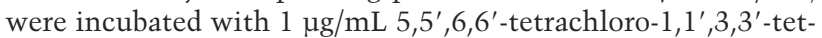
raethylbenzimidazolylcarbocyanine iodide (JC-1; Molecular Probes). The analysis was performed as described (Scaffidi et al. 1999).

\section{Subcellular fractionation and affinity labeling of caspases}

Subconfluent astrocytic cultures transduced with pBabe or Bcl2L $12^{\mathrm{V} 5}$ were stimulated with STS $(1 \mu \mathrm{M})$ for the indicated periods of time, and cytosolic, nuclear, and membrane fractions were prepared using the Protean Kit (Calbiochem) according to the manufacturer's instructions followed by Western blot analysis using caspase-3, cytochrome c, and cytochrome $\mathrm{P} 450$ reductase antibodies. For affinity labeling of caspases, logarithmically growing pBabe and Bcl2L12-expressing astrocytes $\left(6 \times 10^{6}\right.$ cells $)$ were lysed in VAD-buffer (10 mM HEPES-KOH at $\mathrm{pH} 7.4,2 \mathrm{mM}$ EDTA, $0.1 \%$ CHAPS, $5 \mathrm{mM}$ DTT, and protease inhibitors [Roche]). To label active caspases, $40 \mu \mathrm{M}$ biotinylated VAD-fmk (Bachem) was added to lysates and incubated for $45 \mathrm{~min}$ at $37^{\circ} \mathrm{C}$. After precipitation with Streptavidin beads, SDS sample buffer was added, and samples were subjected to SDS-PAGE and subsequent analysis of caspase activation by Western blotting.

\section{Immunohistochemistry and deconvolution immunofluorescence microscopy}

Cells were grown on poly-D-lysine-coated slides (Biocat; Becton Dickinson) and fixed with $2 \%$ paraformaldehyde for $20 \mathrm{~min}$ at 
room temperature. After the fixation, the slides were washed three times with $50 \mathrm{mM} \mathrm{NH}_{4} \mathrm{Cl}$ (in PBS) for $3 \mathrm{~min}$, permeabilized in ice-cold PBS with $0.3 \%$ Triton X-100 for $1 \mathrm{~min}$, washed with PBS-Mg (PBS $\left.+1 \mathrm{mM} \mathrm{MgCl}{ }_{2}\right)$, and incubated for $10 \mathrm{~min}$ in blocking solution (PBS; 5\% BSA). The slides were incubated for $2 \mathrm{~h}$ at room temperature or with the indicated antibodies: antiL12-2 antiserum (1:600), anti-cytochrome c $(1 \mu \mathrm{g} / \mathrm{mL}$; Pharmingen), anti-Golgin 97 (1 $\mu \mathrm{g} / \mathrm{mL}$; Molecular Probes), anti-EEA1 (1 $\mu \mathrm{g} / \mathrm{mL}$; BD Transduction Laboratories), anti-cytochrome P450 reductase $(1 \mu \mathrm{g} / \mathrm{mL}$; Santa Cruz Biotechnologies), anti-XIAP (1 $\mu \mathrm{g} / \mathrm{mL} ; \mathrm{BD}$ Transduction Laboratories), and anti-HMGB1 $(1 \mu \mathrm{g} / \mathrm{mL}$; Abcam). Peptide competition for the anti-L12-2 antiserum was performed as previously described (Schickling et al. 2001). After washing with PBS-Mg, slides were incubated with secondary antibodies $(10 \mu \mathrm{g} / \mathrm{mL}$; AlexaFluor 488 or AlexaFluor 594; Molecular Probes) and DAPI $(2 \mu \mathrm{g} / \mathrm{mL})$ for $1 \mathrm{~h}$ at room temperature, washed, and dehydrated in $100 \%$ ethanol. Slides were analyzed with an Olympus IX70 inverted fluorescence microscope at room temperature. Pictures were acquired using a CM350 CCD camera (Applied Precision) and a 60× oil (Olympus PLAN-APO 1.40NA, $0.10 \mathrm{~mm}$ WD) objective. Forty cross-sections were taken at $0.2-\mu \mathrm{m}$ spacing, and images were deconvolved using 10 cycles with the Ratio method as supplied with the DeltaVision software. The contrast was enhanced for some pictures using the same software. For $Z$-axis analysis, the 30 central images after deconvolution were rotated by $90^{\circ}$ around the $X$-axis.

For Bcl2L12 immunohistochemistry, brain tissue was deparaffinized in xylene, and washed subsequently with $100 \%$ ethanol, $0.5 \% \mathrm{H}_{2} \mathrm{O}_{2}$ in methanol, and $90 \%$ and $70 \%$ ethanol. After rinsing with $\mathrm{PBS}$, slides were microwaved in sodium citrate buffer (pH 6) and cooled on ice for $20 \mathrm{~min}$. After incubation with $10 \%$ NGS in PBS $/ 1 \%$ BSA, slides were incubated with antiL12-2 antiserum (1:1000) overnight at $4^{\circ} \mathrm{C}$, washed three times with PBS, incubated with BGAR (1:500 in PBS/1\% BSA) for 30 $\mathrm{min}$, and further processed with the Vectastain ABC Kit according to the manufacturer's protocol. Slides were put into hematoxylin four times, rinsed with water, and dehydrated.

\section{In vivo xenograft studies}

U87MG cells $\left(2 \times 10^{6}\right)$ were injected either subcutaneously $\left(n=8\right.$ for each U87MG transfectant) or intracranially $\left(1 \times 10^{5}\right)$ into SCID mice ( $n=10$ for each transfectant). For subcutaneous injections, cells were resuspended in Hanks Buffered Salt Solution $\left(2 \times 10^{6}\right.$ cells in $\left.200 \mu \mathrm{L}\right)$, placed on ice, and injected into 6-wk-old SCID animals that were anesthetized with isofluorane. Subcutaneously injected animals were watched closely for tumor development and tumors were isolated 5-6 wk post-injection and weighted to determine tumor mass. For intracranial injections, cells were suspended in Hanks Buffered Salt Solution. Six-week-old SCID mice were anesthetized with ketamine $(60 \mathrm{mg} / \mathrm{kg})$ and xylazine $(7.5 \mathrm{mg} / \mathrm{kg})$ and placed in the stereotactic frame using ear bars. The burr hole in the skull was drilled $0.5 \mathrm{~mm}$ anterior and $2.0 \mathrm{~mm}$ lateral to the Bregma, and cells were injected (total volume $2 \mu \mathrm{L}$ ) at a depth of $3.0 \mathrm{~mm}$ from the surface of the brain. The scalp was closed with 5.0 silk suture. Animals were followed daily for development of neurological deficits. Five animals per transfectant were used to generate survival curves to calculate $\mathrm{ID}_{50}$ values. For pathological analyses, all animals were deeply anesthetized, and brains were fixed by intracardiac perfusion with $4 \%$ paraformaldehyde followed by a further $12 \mathrm{~h}$ of immersion fixation. For histological analyses, entire brains were sectioned in 1-2-mm coronal blocks, and paraffin-embedded sections were processed for hematoxylin and eosin $(\mathrm{H} \& \mathrm{E})$ by standard techniques. For immu- nohistochemical analysis, sections were subjected to an antigen retrieval process using a sodium citrate buffer in preparation for BrdU, TUNEL, and active caspase-3/active caspase-7 staining (1:50; Calbiochem) according to standard protocols.

\section{Acknowledgments}

We are grateful to Dr. Emnad Alnemri for providing us with the cDNAs for caspase-7 and caspase-9, to Dr. Frank Furnari for the glioma cell lines, and to Dr. Stanley Korsmeyer for helpful discussions. We also extend our thanks to Drs. John Quackenbush and David Harrington for advice on statistical analyses. We thank the electron microscopy facility of Harvard Medical School for help with ultrastructural analysis of astrocytes and the FACS facility of the Dana-Farber Cancer Institute for their help with flow cytometric analyses. A.H.S. is supported by grants from the German Research Foundation (Emmy-Noether Fellowship) and the Claudia Adam Barr Foundation, and R.M.B. is supported by NIH grant K08NS42737. This work is supported by NIH grants PO1 CA95616 (to R.A.D., D.N.L., and L.C.), RO1 CA099041 (to L.C.), and RO1 CA57683 (to D.N.L.), and by a brain tumor research award from the Bernard A. and Wendy J. Goldhirsh Foundation and from the James S. McDonnell Foundation for the 21 st century research award to L.C.

\section{References}

Aoyama, A., Steiger, R.H., Frohli, E., Schafer, R., von Deimling, A., Wiestler, O.D., and Klemenz, R. 1993. 1993. Expression of $\alpha$ B-crystallin in human brain tumors. Int. J. Cancer 55: 760-764.

Brat, D.J. and Van Meir, E.G. 2004. Vaso-occlusive and prothrombotic mechanisms associated with tumor hypoxia, necrosis, and accelerated growth in glioblastoma. Lab. Invest. 84: 397-405.

Denault, J.B., Bekes, M., Scott, F.L., Sexton, K.M., Bogyo, M., and Salvesen, G.S. 2006. Engineered hybrid dimers: Tracking the activation pathway of caspase-7. Mol. Cell 23: 523-533.

Ferri, K.F. and Kroemer, G. 2001. Mitochondria-The suicide organelles. Bioessays 23: 111-115.

Fujita, E., Egashira, J., Urase, K., Kuida, K., and Momoi, T. 2001. Caspase- 9 processing by caspase- 3 via a feedback amplification loop in vivo. Cell Death Differ. 8: 335-344.

Ginzinger, D.G. 2002. Gene quantification using real-time quantitative PCR: An emerging technology hits the mainstream. Exp. Hematol. 30: 503-512.

Glaser, T. and Weller, M. 2001. Caspase-dependent chemotherapy-induced death of glioma cells requires mitochondrial cytochrome c release. Biochem. Biophys. Res. Commun. 281: 322-327.

Hahne, M., Kataoka, T., Schroter, M., Hofmann, K., Irmler, M., Bodmer, J.L., Schneider, P., Bornand, T., Holler, N., French, L.E., et al. 1998. APRIL, a new ligand of the tumor necrosis factor family, stimulates tumor cell growth. I. Exp. Med. 188: 1185-1190.

Hao, C., Beguinot, F., Condorelli, G., Trencia, A., Van Meir, E.G., Yong, V.W., Parney, I.F., Roa, W.H., and Petruk, K.C. 2001. Induction and intracellular regulation of tumor necrosis factor-related apoptosis-inducing ligand (TRAIL) mediated apotosis in human malignant glioma cells. Cancer Res. 61: 1162-1170.

Hitotsumatsu, T., Iwaki, T., Fukui, M., and Tateishi, J. 1996. Distinctive immunohistochemical profiles of small heat shock proteins (heat shock protein 27 and $\alpha$ B-crystallin) in 
human brain tumors. Cancer 77: 352-361.

Houde, C., Banks, K.G., Coulombe, N., Rasper, D., Grimm, E., Roy, S., Simpson, E.M., and Nicholson, D.W. 2004. Caspase-7 expanded function and intrinsic expression level underlies strain-specific brain phenotype of caspase-3-null mice. J. Neurosci. 24: 9977-9984.

Jiang, Z., Zheng, X., and Rich, K.M. 2003. Down-regulation of Bcl-2 and Bcl- $\mathrm{x}_{\mathrm{L}}$ expression with bispecific antisense treatment in glioblastoma cell lines induce cell death. J. Neurochem. 84: 273-281.

Kamradt, M.C., Chen, F., and Cryns, V.L. 2001. The small heat shock protein $\alpha$ B-crystallin negatively regulates cytochrome c- and caspase-8-dependent activation of caspase-3 by inhibiting its autoproteolytic maturation. J. Biol. Chem. 276: 16059-16063.

Kamradt, M.C., Lu, M., Werner, M.E., Kwan, T., Chen, F., Strohecker, A., Oshita, S., Wilkinson, J.C., Yu, C., Oliver, P.G., et al. 2005. The small heat shock protein $\alpha$ B-crystallin is a novel inhibitor of TRAIL-induced apoptosis that suppresses the activation of caspase-3. J. Biol. Chem. 280: 11059-11066.

Kato, S., Hirano, A., Kato, M., Herz, F., and Ohama, E. 1993. Comparative study on the expression of stress-response protein $(\operatorname{srp}) 72, \operatorname{srp} 27, \alpha$ B-crystallin and ubiquitin in brain tumours. An immunohistochemical investigation. Neuropathol. Appl. Neurobiol. 19: 436-442.

Kleihues, P., Louis, D.N., Scheithauer, B.W., Rorke, L.B., Reifenberger, G., Burger, P.C., and Cavenee, W.K. 2002. The WHO classification of tumors of the nervous system. J. Neuropathol. Exp. Neurol. 61: 215-225.

Korfali, N., Ruchaud, S., Loegering, D., Bernard, D., Dingwall, C., Kaufmann, S.H., and Earnshaw, W.C. 2004. Caspase-7 gene disruption reveals an involvement of the enzyme during the early stages of apoptosis. J. Biol. Chem. 279: 10301039.

Lakhani, S.A., Masud, A., Kuida, K., Porter Jr., G.A., Booth, C.J., Mehal, W.Z., Inayat, I., and Flavell, R.A. 2006. Caspases 3 and 7: Key mediators of mitochondrial events of apoptosis. Science 311: 847-851.

Leist, M., Single, B., Castoldi, A.F., Kuhnle, S., and Nicotera, P. 1997. Intracellular adenosine triphosphate (ATP) concentration: A switch in the decision between apoptosis and necrosis. J. Exp. Med. 185: 1481-1486.

Lin, B., Kolluri, S.K., Lin, F., Liu, W., Han, Y.H., Cao, X., Dawson, M.I., Reed, J.C., and Zhang, X.K. 2004. Conversion of Bcl-2 from protector to killer by interaction with nuclear orphan receptor Nur77/TR3. Cell 116: 527-540.

Maher, E.A., Furnari, F.B., Bachoo, R.M., Rowitch, D.H., Louis, D.N., Cavenee, W.K., and DePinho, R.A. 2001. Malignant glioma: Genetics and biology of a grave matter. Genes \& Dev. 15: 1311-1333.

Mathioudaki, K., Scorlias, A., Papadokostopoulou, A., Xynopoulos, D., Arnogianaki, N., Agnanti, N., and Talieri, M. 2004. Expression analysis of BCL2L12, a new member of apoptosisrelated genes, in colon cancer. Biol. Chem. 385: 779-783.

McCarthy, K.D. and de Vellis, J. 1980. Preparation of separate astroglial and oligodendroglial cell cultures from rat cerebral tissue. J. Cell Biol. 85: 890-902.

Miyazaki, K., Yoshida, H., Sasaki, M., Hara, H., Kimura, G. Mak, T.W., and Nomoto, K. 2001. Caspase-independent cell death and mitochondrial disruptions observed in the Apaf1deficient cells. J. Biochem. 129: 963-969.

Moyano, J.V., Evans, J.R., Chen, F., Lu, M., Werner, M.E., Yehiely, F., Diaz, L.K., Turbin, D., Karaca, G., Wiley, E., et al. 2006. $\alpha \mathrm{B}$-Crystallin is a novel oncoprotein that predicts poor clinical outcome in breast cancer. J. Clin. Invest. 116: 261-270.
Nagane, M., Levitzki, A., Gazit, A., Cavenee, W.K., and Huang, H.J. 1998. Drug resistance of human glioblastoma cells conferred by a tumor-specific mutant epidermal growth factor receptor through modulation of $\mathrm{Bcl}-\mathrm{X}_{\mathrm{L}}$ and caspase-3-like proteases. Proc. Natl. Acad. Sci. 95: 5724-5729.

Naviaux, R.K., Costanzi, E., Haas, M., and Verma, I.M. 1996 The pCL pBabe system: Rapid production of helper-free, high-titer, recombinant retroviruses. J. Virol. 70: 5701-5705.

Nicotera, P. and Melino, G. 2004. Regulation of the apoptosisnecrosis switch. Oncogene 23: 2757-2765.

Pelengaris, S., Khan, M., and Evan, G. 2002. c-MYC: More than just a matter of life and death. Nat. Rev. Cancer 2: 764-776.

Raza, S.M., Lang, F.F., Aggarwal, B.B., Fuller, G.N., Wildrick, D.M., and Sawaya, R. 2002. Necrosis and glioblastoma: A friend or a foe? A review and a hypothesis. Neurosurgery 51: $2-12$.

Roth, W., Isenmann, S., Nakamura, M., Platten, M., Wick, W. Kleihues, P., Bahr, M., Ohgaki, H., Ashkenazi, A., and Weller, M. 2001a. Soluble decoy receptor 3 is expressed by malignant gliomas and suppresses CD95 ligand-induced apoptosis and chemotaxis. Cancer Res. 61: 2759-2765.

Roth, W., Wagenknecht, B., Klumpp, A., Naumann, U., Hahne, M., Tschopp, J., and Weller, M. 2001b. APRIL, a new member of the tumor necrosis factor family, modulates death ligand-induced apoptosis. Cell Death Differ. 8: 403-410.

Saito, R., Mizuno, M., Hatano, M., Kumabe, T., Yoshimoto, T., and Yoshida, J. 2004. Two different mechanisms of apoptosis resistance observed in interferon- $\beta$ induced apoptosis of human glioma cells. J. Neurooncol. 67: 273-280.

Scaffidi, C., Schmitz, I., Zha, J., Korsmeyer, S.J., Krammer, P.H., and Peter, M.E. 1999. Differential modulation of apoptosis sensitivity in CD95 type I and type II cells. J. Biol. Chem. 274: 22532-22538.

Scaffidi, P., Misteli, T., and Bianchi, M.E. 2002. Release of chromatin protein HMGB1 by necrotic cells triggers inflammation. Nature 418: 191-195.

Schickling, O., Stegh, A.H., Byrd, J., and Peter, M.E. 2001. Nuclear localization of DEDD leads to caspase-6 activation through its death effector domain and inhibition of RNA polymerase I dependent transcription. Cell Death Differ. 8: 1157-1168.

Schimmer, A.D., Welsh, K., Pinilla, C., Wang, Z., Krajewska, M., Bonneau, M.J., Pedersen, I.M., Kitada, S., Scott, F.L., Bailly-Maitre, B., et al. 2004. Small-molecule antagonists of apoptosis suppressor XIAP exhibit broad antitumor activity. Cancer Cell 5: 25-35.

Scorilas, A., Kyriakopoulou, L., Yousef, G.M., Ashworth, L.K., Kwamie, A., and Diamandis, E.P. 2001. Molecular cloning, physical mapping, and expression analysis of a novel gene, BCL2L12, encoding a proline-rich protein with a highly conserved $\mathrm{BH} 2$ domain of the Bcl-2 family. Genomics 72: 217221.

Slee, E.A., Harte, M.T., Kluck, R.M., Wolf, B.B., Casiano, C.A., Newmeyer, D.D., Wang, H.G., Reed, J.C., Nicholson, D.W., Alnemri, E.S., et al. 1999. Ordering the cytochrome $c$-initiated caspase cascade: Hierarchical activation of caspases-2, $-3,-6,-7,-8$, and -10 in a caspase-9-dependent manner. J. Cell Biol. 144: 281-292.

Stennicke, H.R. and Salvesen, G.S. 1999. Caspases: Preparation and characterization. Methods 17: 313-319.

Strik, H., Deininger, M., Streffer, J., Grote, E., Wickboldt, J., Dichgans, J., Weller, M., and Meyermann, R. 1999. BCL-2 family protein expression in initial and recurrent glioblastomas: Modulation by radiochemotherapy. I. Neurol. Neurosurg. Psychiatr. 67: 763-768.

Talieri, M., Diamandis, E.P., Katsaros, N., Gourgiotis, D., and 
Scorilas, A. 2003. Expression of BCL2L12, a new member of apoptosis-related genes, in breast tumors. Thromb. Haemost. 89: 1081-1088.

Thomadaki, H., Talieri, M., and Scorilas, A. 2006. Prognostic value of the apoptosis related genes BCL2 and BCL2L12 in breast cancer. Cancer Lett. Epub ahead of print May 2, 2006; doi:10.1016/j.canlet.2006.03.016.

Vaux, D.L. and Silke, J. 2005. IAPs, RINGs and ubiquitylation. Nat. Rev. Mol. Cell Biol. 6: 287-297.

Zhang, J., Ren, H., Yuan, P., Lang, W., Zhang, L., and Mao, L. 2006. Down-regulation of hepatoma-derived growth factor inhibits anchorage-independent growth and invasion of nonsmall cell lung cancer cells. Cancer Res. 66: 18-23.

Zheng, T.S., Hunot, S., Kuida, K., Momoi, T., Srinivasan, A., Nicholson, D.W., Lazebnik, Y., and Flavell, R.A. 2000. Deficiency in caspase-9 or caspase-3 induces compensatory caspase activation. Nat. Med. 6: 1241-1247.

Zhou, Z., Yamamoto, Y., Sugai, F., Yoshida, K., Kishima, Y., Sumi, H., Nakamura, H., and Sakoda, S. 2004. Hepatomaderived growth factor is a neurotrophic factor harbored in the nucleus. J. Biol. Chem. 279: 27320-27326.

Zhu, Y. and Parada, L.F. 2002. The molecular and genetic basis of neurological tumours. Nat. Rev. Cancer 2: 616-626.

Zong, W.X. and Thompson, C.B. 2006. Necrotic death as a cell fate. Genes \& Dev. 20: 1-15. 


\section{Erratum}

Genes \& Development 21: 98-111 (2007)

Bc12L12 inhibits post-mitochondrial apoptosis signaling in glioblastoma

Alexander H. Stegh, Hyunggee Kim, Robert M. Bachoo, Kristin L. Forloney, Jean Zhang, Harald Schulze, Kevin Park, Gregory J. Hannon, Junying Yuan, David N. Louis, Ronald A. DePinho, and Lynda Chin

In the above mentioned paper, the molecular weight markers for the caspase- 3 Western blot shown in Figure $2 \mathrm{C}$ (middle panel) were incorrect. The corrected figure appears below. This change does not affect the findings or conclusions of the paper.

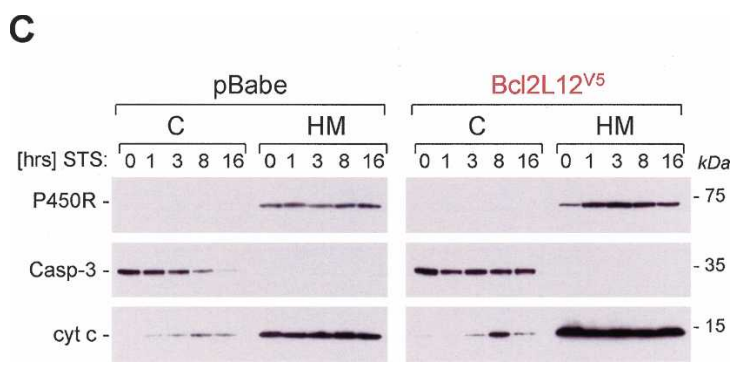




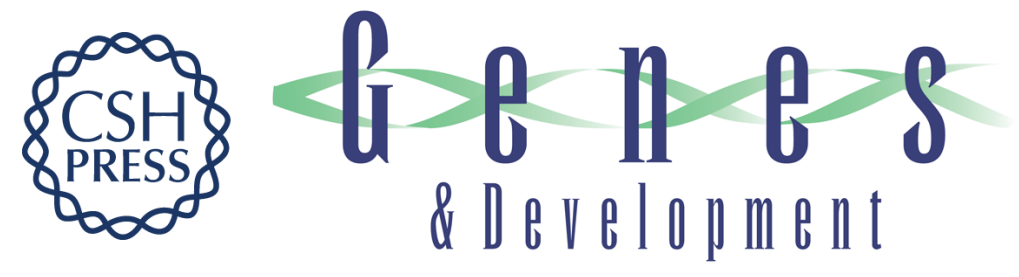

\section{Bcl2L12 inhibits post-mitochondrial apoptosis signaling in glioblastoma}

Alexander H. Stegh, Hyunggee Kim, Robert M. Bachoo, et al.

Genes Dev. 2007, 21:

Access the most recent version at doi:10.1101/gad.1480007

\section{Supplemental http://genesdev.cshlp.org/content/suppl/2007/01/18/21.1.98.DC1 Material}

\section{Related Content}

Erratum

Genes Dev. February , 2007 21: 481

References This article cites 48 articles, 19 of which can be accessed free at: http://genesdev.cshlp.org/content/21/1/98.full.html\#ref-list-1

Articles cited in:

http://genesdev.cshlp.org/content/21/1/98.full.html\#related-urls

\section{License}

Email Alerting

Service

Receive free email alerts when new articles cite this article - sign up in the box at the top right corner of the article or click here.

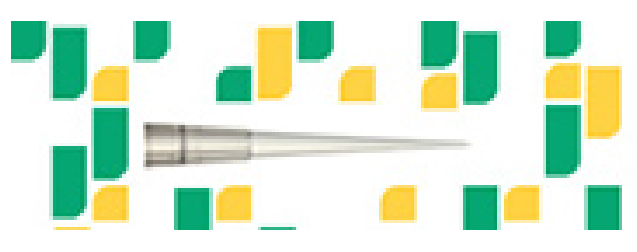

Focused on your science. 